\section{3.К. Айламазян}

НИИ акушерства и гизекологии им. Д.О. Отта РАМН, Санкт-Петербург

\section{ОСНОВНЫЕ ПРОБЛЕМЫ И ПРИКЛАДНОЕ ЗНАЧЕНИЕ ЭКОЛОГИЧЕСКОЙ РЕПРОДУКТОЛОГИИ}

Экологическая репродуктология это область медицинских знаний, предметом которой яв.яяется изучение экологическн зависимьх адапташнонноприспособительньх и патологических реакณнй репродуктивной функшии человека. Система бноэколопической диагностикн окружающей среды по показателям репродуктивной функши женшнны позволяет создать достоверное информационное поле для принятия управленческих решений и предотвратить часть репродуктнвньх потерь, сохранить и улучшкть здоровье женичины и ее потомства.

- Ключевые стова: экологическая репродуктология; релродуктивное здоровьс женшин; окружаюшая среда
K началу XXI века экологическая обстановка в России и в большинстве других стран мира не имеет тендснции к стабилизации. В ряде регионов вектор экологических процессов налравлен в худшую сторолу. Репродуктивная функщия женского организма особо чувствительна к внешним воздействиям вредных факторов окружаюшей среды любой, даже малой интенсивности. Женцины репродуктивного возраста (особенно беременные, роженицы, родильницы, кормящие матери), дети, подростки наиболее уязвимые группы населения, т. е. группы риска, требующие дополнительной защиты: социальной, медицинской, психологической. Одной из основных причин демографического кризиса в России можно считать ухудшение релродуктивного здоровья населения.

Сохранение репродуктинного здоровья населения страны является одной из ключевых медико-социатьных проблем, важным фактором национальной безопасности. Это понятие включает в себя целый комплекс медико-экологических вопросов. Приоритетными задачами в этой области являются: улучшение качества жизни, зцоровья и увеличение продолжительности жизни путем снижения неблагонриятного возцействия экологических факторов и профилактика экологически зависимых состояний.

Репродуктивная функция является важнейшим интегральным показателем здоровья женшины, определяет качество ее жизни и ее потомства, а соответственно, здоровье и качество жизни нации. ГІо последним официальным данным в России сейчас проживает более 76,7 млн женщин. Половина из них находится в экономически активном возрасте. Уровень занятости женщин в трудовой деятельности составляет более $75 \%$.

В течение последних 50 лет внимание врачей, главным образом гигиенистов и грофпатологов,а также и акушеров было сосредоточено на изучении неблагоприятного влияния различных факторов (реже их сочетания) производственной среды на организм женщины вне и во время беременности, на организм плода и новорожденного ребенка. Результаты такого рода исследований составили практически важную часть репродуктологии - профессиональную или производственную, в которой отечественные ученые и практики всегда занимали лидируюшее положение, в том числе и в нашии дни.

В рамках Проблемной комиссии «Экология и репродуктивное здоровье женшин” мы проанализировали результаты комплексного (анамнестического, киинического, биохимического, иммунологического, гормонатьного, микробиологического, инструментального) обследования работниц нефтехимической, нефтеперерабатывающей, химической промышленности, резиново-технического, хромового производства, электронной промьшленности, трансформаторного, медеплавильного, титаново-магниевого производства; женшин занятьх в машиностроении, металлургии, полимерперерабатывающей, газовой, 
горнодобывающсй промышленности, в текстильном, целлюлозно-бумажном производстве, сельском хозяйстве и др. В общей сложности изучено состояние релродуктивной функции почти у 300 тыс. желщин вне и во время беременности и состояние здоровья более чем 60 тыс. их новорожленных. При сопоставлении јолученных данных мы обратили внимание на 3 важнейнгих обстоятельства:

Во-первых, заметное ухудшение репродуктивного здоровья имело мссто у женшин, работаюших на производствах, где по официальным данным ПДК вредных вешеств были, как правило, в гиределах нормы.

Во-вторых, структура осложнений беременности у обследованных женццин - работниц различных лредприятий включата практически весь спектр известных патологичсских процессов в плодово-птацентарно-маточном комплексе.

В-третьих, спектр и частота акунгерской и гинекологической патологии у женшин, занятых в разных отраслях промышленности, были очень близкими, нередко одинаковыми.

В определенной мере эти положения применимы и к так называемой территориатыной или климатической репродуктологии, изучаюшей воздействие экстремальных условий среды обитания (аридные зоны, высокогорье, комплекс условий Крайнего Севера и т. п.) на релролуктивную функцию женщины.

За десятилетия интенсивной научно-практической деятельности в этой области накоплены многочисленные факты больлой ценности. Постепенно пришло понимание того, что женшина подвергается воздействию неблаголриятных факторов повсеместно и ежечасно не только на производстве, но и на улицах городов, в транспорте, в быту. Речь идет о влиянии загрязненной атмосферы, воды и почв, пыли и шума, СВЧ-лолн, электромагнитных излучений, радиации; большого арсенала косметичсских и гигиенических средств и средств бытовой химии. Стало жсно, что наибольший вклад в разрушение здоровья людей вносит не производственная среда как таковая, а в первую очередь вся окружающая среда крупных городов, в которых ссйгас проживает 67\% населения России. В них действует весь комплекс неблагоприя'тных факторов урбанизации, в том числе обостряющиеся социальныс и психологические процессы. Темпы техногенных изменений биосферы на фоне обостряющихся социальных и психологических процессов олережают алаптационные возможности чслонеческого организма, других живых организмов и требуют всс большего дополнитсльного налрљжения адаптивных механизмов.

В последние годы мы все чапте говорим об угрозе разрушения природной и социально-экономической среды. Болсе 15 лет назад в стране были официально названы районы экологического бедствия. К ним отнесены: почти вся евролейская часть России (особенно Среднес Поволжье); Кольский полуостров; районы, зараженные в результате аварии в Чернобьле, а также Урал; промышленные районы Сибири и Дальнего Востока; вІгуренние бассейны: Каспийское, Черное, Баттийское море, Ладожское озеро. В этих районах проживает сейчас более половины населения России. Но в конце $2002-$ начале 2003 года, по данным Центров Госсанэпилналзоров, в ряде регионов России отмечается стабилизацци, а в некоторых областях и улучшение показателей антропогенной нагрузки (т. е. улучшение качества воздушной среды, воды, почв) по результатам оценки предельно допустимых концентраций. Гигиеническое контролирование остается важной и нсотъемлемой частью экологического нормирования средь, и в этом смысле оно абсолютно необходимо. Но на базе одыих только данных о предельно допустимых концентрациях невозможны обобшения экосистемного уровня, необходимость в которых возрастает из года в год.

Усиление неблагогриятных тенценций в динамике экологического состояния большинства регионов страны совлало с беспрецедентным для России демографическим кризисом. Сокрашение средней продолжительности жизли, высокая смертность и низкая рожласмость определяют состояние демографии в России как постеленное «снижение потенциала нации», находящейся на грани вымирания. Ужс более десятилетия смертность населсния гревышает рождаемость, и, соответственно, естественный прирост населения остастся величиной огрицательной: в 2003 году в Российской Федерации он составил 6,2 , а по Ссверо-Западному Федеральному округу $-8,9$, что не обеслечивает простого замещения поколений. Одной из важных причин демографического неблагополучия следует считать снижение числа женшин цетородного возраста и существснное ухушшсние их здоровья. Это неизбсжно и необратимо влияет на состояние здоровья их детей, приводит к высокой младенческой, детской смертности, перинатальной и детской заболеваемости, инвалидности детей и лодростков.

Несмотря ла некоторую стабилизацию и снижение уровня антропогенного загрязнсния ок- 
ружающей среды, ло данным параметров санитарно-гигиенического мониторинга в 2000-е годы ло ряду различных регионов Российской Федерации, и улучшение качества оказания медицинской помоци неизбежным откликом на деграцацию окружающей, в том числе социальной и шромышленной среды, стальо неуклонное ухудшение показателей злоровья населения Российской Федерации, о чем свидетельствуют материаты Государственных докладов о состоянии здоровья населения Российской Федерации всех последних лет. Прирост заболевасмости в 2003 году по сравнению с 2001 годом составил 7300,9 чејовек на 100000 населения. Нсуклонно нарастает заболеваемость новорожденных, детей и подростков. Число женщин с осложненным течением беременности и родов остастся на очень высоком уровне. В Сенеро-Западном Фсдеральном округе в 2003 году этот показатель составил 63\%, а по Российской Федерации 68,3\%. В 2003 году почти у каждой желшилы репродуктивного возраста зарегистрировано не менее чем по 2 хронических заболевания

За последние 10 лет в Российской Федерации нарастаст число аномалий у детей - цо 17,2 на 1000 паселелия в группе от 0 до 14 лет; высокими темлами увеличивается число детсй инвалидов на 30-40 тигсяч н год; число детей до 16 лет, получающих социальную пенсию, в последние годы превышает 0,5 млн человек. Среди заболеваний, обусловивших возникловецие инвалидности у детей в возрасте $0-17$ лет по Российской Федсрации, наблюдается рост болезней эндокринной системы, расстройств питания, нарушений обмена веществ с 10,2 на 10000 соответствующего населения в 2002 году до 10,5 в 2003 году, а психических расстройств соответственно с 42,6 в 2002 году до 44,7 в 2003 году на фоне относительно стабильной заболеваемости другими нозологическими сдиницами. Проблсма увеличения числа детей-инвалидов поставила в перечень национальных приоритетов в России профилактику детской инвалидности. Остается высоким уровень гинекологической заболеваемости. 3 а последние 5 лет уровень заболеваемости на 100000 женского населения эндометриозом увеличился на $36,2 \%$, нарушениями в перименопаузальном периоде - в 1,9 раза. На 27\% ныросла заболеваемость расстройствами менструации, в 1,5 раза увеличилась частота осложнений беременности, родов и послероцового периода, на 8,6\% - воспалительными заболеваниями придатков матки, на 4,3\%женским бесллодием. Неуклонно растет число злокачественных новообразований. Прирост этого показателя в 2003 голу составил 88,1 на 100000 населения России по сравнению с 1980 годом. Первое место по распространенности в женской популяции принадлежит новообразованиям молочной железы (19,4\%).

Необходимо отметить, что в комплексе неблагоприятных влияний на организм женщины и ее фертильность находят значимое место вредные лривычки: курсние, употребление аткоголя, пристрастие к токсическим и наркотическим вешестнам. Этот факт уже можно назвать социальным бедствием. Наглядным примером служат показатели заболеваемости населения России психическими расстройствами, связанньми с употреблением Ісихоактивных вещестн.

Вопрос вопросов экологической релродуктологии - можно ли выявить и доказать связь каждого или хогя бы некоторых факторов окружающей среды, онениваемых с помощью предельно допустимых велитин, с той или иной патологией, в том числе репродуктивной системьг. На него, к сожалению, может быть только отрицательный ответ. Когда речь идет об индикации среды, оперативном и/или проспективном слежении за состоянием экологи'еской обстановки, подразумевается оценка и мониторинг суммы всех положительных и отрицательных, гіостоянных и переменных, биотических и абиотических факторов, влияюцци на среду обитания. Интегральным показателем является безусловно здоровье человека.

В начале 90-х годов мы сформулировали концепцию, согласно которой количествснно измеряемые показатели репродуктивной функции женщины могут быть критериями интегральной оненки-н контроля бкружающей среды.-Нами был предложен ком $\bar{\Pi} \overline{\bar{\kappa}} \mathrm{c}$ Показателей, необходимых и достаточных для оперативной оценки, сравнения и контроля экологичсской ситуации в регионе. Разработанный на этой основе способ оценки окружающей среды по показателям репродуктивной функции желщины защищен Патентом Российской Федерации от 1998 года (Патент № 2118817 РФ от 10 сентября 1998 года). В дальнейшем мы доказали их экодиагностическую ценность и рабогоспособность для мониторинга среды обитания. Это следуюшие показатели: частота угрозы прерынания беременности, гестозов, самопроизвольных абортов, преждевременных родов, преждевременного излития околоплодных вод, аномалий родовой деятельности, перинатальная смертность, заболеваемость новорожденных, частота гормональной недостаточности яичников, гиперплазии эндометрия, возраст менопаузы, степень 
тяжссти течения климақтерического синдрома, частота фиброаденоматоза молочной железы и встречаемости миомы матки.

Премией Правительства Российской Федерации в области науки и техники за 2001 гол была отмечена работа коллсктива хорошо известных в стране и за рубежом исследовағелей, в течение ряла лет успешно разрабатывающих проблему неблагоприятного воздействия различных факторов окружаюшей среды на репродуктивное здоровье женшины, «Разработка и внедрение мер по охране репродуктивного здоровья женщин при воздействии вредных факторов окружающей, в том числе производственной среды». В него вошли ученые из Москвы, СанктПетербурга, Ростова-на-Дону: академик РАМН з. д. н. РФ профессор Э.К. Айламазян (НИИ акушерства и гинекологии им. Д.О.Отта РАМН); з. Д. н. РФ профессор В.В. Потин (НИИ АГ им. Д.О. Отта РАМН); з. Д. Н. РФ профессор Н.Г. Кошелева (НИИ АГ им. Д.О. ОтТа РАМН); профессор О.В.Сивочалова (НИИ медилины труда РАМН); профессор В.П. Чашин (СевероЗаладный НЦ гигисны и обшествениого здоровья МЗ РФ); профессор А.А. Кожин (Ростовский НИИ акушерства и педиатрии МЗ РФ); д. 6. н Э.Н. Денисов (НИИ медицины труда РАМН).

Российская наука всегда занимала лидирующее положенис в изучении влияния вредных факторов окружаюшей, в том числе промыщленной среды на здоровье женшцины и се потомство. Работа, удостоенная Прсмии Правительства РФ в области науки и техники, включает в себя фундаментальные и лрикладные исследования (экспериментальные, клинические, эпидемиологические и другие), а также лрактические разработки для решения актуальной медико-социальной проблемы современной России. Работа охватила период с 1990 по 2000 год с параллельным проведением научных исследований и практической реализации результатов.

Таким образом, мы считаем, что в настояшее время сложились все условия цля обобшения накоплснных данных о феноменологии нарушений релродуктивного здоровья под вынянием факторов окружающей среды, выявлелия закономерностей такого влияния, определения их научного и практического значения. Иными словами, из комплекса экологических и медицинских наук выделилась специальная дисциплинарная область - экологическая репродуктология. Экологическая репродуктология - это область медицинских знаний, прсдметом которой является изучение экологически зависимых аналтационно-лрислособительцых и патологических реакций репродуктивной системы человека. Задачи экологической релродуктологии в самом обшем виде можно сформулировать как всестороннее изучение процессов адаптации репродуктивной сферы к воздействию природных, щроизводственных, социальных и психологических Факторов в различных сочетаниях и в разных физико-георафнческих зонах. При этом речь идет, с одной стороны, об индивидуальных особенностих экололически зависимых реакций репродуктивной системы, а с другой, - об особенностях фертильности понуляции людей, проживающих в разных биогеохимических ареалах.

Эффективность и практическая ценность концепции экологической репродуктологии зависит от методологически безупречной организации изучения феноменологии адаптационного гроцесса на воздействие патогенных факторов среды отвста организма в целом, но с указанисм уровня поврежпения. Не меньшее значение имсст использование приемов и методов эгицемиологического анализа јсля оценки популяционного типа адаптации.

Среда обитания человека постоянно меняется. Человек постоянно сталкивается с новыми факторами среды, ранее никогда не встречавшимися на протяжении всей его эволюции, испытывает большие «нагрузки» социального и экологического характсра. Ускоренный научно-технический прогресс без учета экологических проблем может щриблизить человечество к нарушению его биологической гармонии со срелой. При чрезвычайном заюрязнении окружаюшей среды может нарушиться равповесие генегических процессов, обеспсчиваюшее подцержание наследственного гомсостаза. Это будет означать конец биологическому виду Homo sapiens. Постояниый уровень мугационного процесса, оптимальный для человека, может повышаться от многих физических, химических и биологических факторов. Если мутации возникают в зародышгевых ктетках, то это приводит к повышению частоты наследственной патологии, врожденных пороков развития, гибели эмбриона или глода, внутриутробной задержки роста, частоты мутации в клетках эмбриона и плода. Мутационный пролесс в соматических клетках в постнатальный период повышает частоту возникновения злокачественных новообразований, нарушает иммунитет, обусловливает преждевременное старенис. Однако популяционные генетические процессы обладают большой силой инерции, поэтому не следует ожидать, что мутационный процесс и экогенетические реакции могут в течение 1-2 поколений вызвать рез- 
кое увсличение частоты наследственных болезғей. Утверждение об ухудшении генофонда человечества к настоящему моменту надо относить скорее к политическому пиару, чем к научно обоснованным заключениям. Экологи и генетики должны выполнить свок главную задачу по сохранению наследственности чсловска - этого бесценного дара эволюции, который передается из поколения в поколение. Іотомки не должны страдать от экологической небрежности предков.

Требует особого обсуждения необходимость изучения конституциональғого комгонента реактивности организма. «Конституционаіьно состав'lя ющая» экологической адаптации, изученная с привлечением алскватньх методов оценки центральной и вегетативной нервлой систем, высшей нервной дсятельности, гормональной и иммунной систем с учетом доступных для выявления генетически обусловленных индивидуапьных признаков, позволит, на наш взгляд, решительно продвинуться в понимании суги экологической адаптации и путей эффективной профилактики зкозависимой патологии вообще и репродуктивной патологии в частности.

В практическом плане общей экологической рслродуктологии принадлежит объединяюшая, связуюшая роль. В рамках клинической медицины ее предметной областью является болезнь, патология. Спектр экологичсски зависимой гатологии весьма широк и охватывается такими клини'ескими дисшиг'инами, как акушерство, гинекология, перинатология, неонатология, пециатрия, меџицинская гснетика, незропатология, психиатрия, анцрология и др. Можно не сомневаться в том, что этот список будет со временем расширяться: истинных масштабов экојогической агрессии ға релролуктивную функшию человека сейчас не знает никто.

Социальное значение экологической релродуктологии исключительно велико. Достаточно сказать, что она является областью медицинской науки и практики, формирующейся в интересах обшественной и инцивидуальной профилактики болезней, олределяюцих уровень здоровья населения страны в настоянем и будушем. С этой точки зрения, экологическая репролуктология - часть профилактической медицины, и ее место в профилактической медицине и практическом здравоохранении приближаются к ключевому.

Основные положения экологической рспродуктологии можно сформулировать следующим образом (Э.К. Айламазян, 1992):

- Репродуктивная система женшины высоко и особо чувствительна к воздействию неблаГоп- риятных факторов среды любого лроисхождения и любой интенсинности, в том числе подпороговой.

- В формировании экологически зависимой патологии репродуктивной системы имејот зачение специфические, неспецифические (с преобладанисм неспецифических обшепатологических) и конституционаіьные факторы.

- Экологически зависимые нарушсния проявляюгся клиническими, патофизиологическими, гормональными, биохимическими, иммунологическими симптомами, которые имеют большюе сходство при воздействии разных природных и антропогенных факторов и в большинстве случаев носят однонаправленный, однотипньй характер.

- В клиническом (акушерском, гинекологическом, перинатальном и ледиатрическом) отнощении возникаюшис расстройства выражаются снижением фертильғости, учашением патология беременности и родов, повышением частоты нарушений менструальлого цикла, повышением частоты гиперпластических процессов, неспецифических хронических воспалительных заболеваний половых органов, ухудшением состояния плода и его гибелью вследствие гипотрофии, гилоксии, пороков развития, снижением качества здоровья новорожденного, увеличением неонатальных потерь, инвалидизацией детей и подростков. Выраженность неблагоприятного воздействия природной и техногенной среды и предел устойчивости к ним организма женщины определяются ее фенотипом, возрастом, профессией и стажем, условиями быта, характером и выражегностью спенифических и неспецифических повреждаюших агентов, их сочетаниями и интенсивностью воздействия (т. е. дозой и экслозицией).

Экологически зависимые изменения в репродуктивной сфере женшины развинаются трехфазно. Исход беременности и родов, «судьба" плода и новорожденного зависят от того, в какой фазе адаптации к агрессии окружаюшей срсды наступила беременность и протекала большая часть развития плода.

Первая фаза - острая дезадаптация. Она продолжается обычно около 3-х лет и характеризуегся появлением острых нарушений репродуктивной функции. Они проявляются гормолальной нсдостаточностью яичников, дисфункциональными маточными кровотечениями, острыми и подострыми воспалительными заболеваниями половых органов, гестозом и невынашиванием беременности. 
Вторая фаза - хроническая субкомпенсация, сопровождающаяся некоторым улучшением локазателей репродуктивного здоровья. Она чродолжается несколько лет и объясняется доссижением нового уровня адаптации организма женшины к действию неблагоприягных факторов окружаюшей среды, природной, техногенной, в том числе производственной.

Третья фаза - декомпенсация, или истощепие адаптивных возможностей организма. В этот период появляются стойкие, часто необратимые нарушения репродукции.

Вредному воздействию неблагоприятных факторов среды обитания подвергаются также половые клетки и ранние стадии формирования эмбриона.

Экологически зависимая патология репролуктивной системы формируется при нарушении всех типов адаптации: молекулярного, надмолекулярного, клеточного, тканевого, системного, регуляторного, адаптации организма, адаптации популящии и социальной адаптации.

На наш взгляд, работы, направленные на изучение и решение общих и частных вопросов экологической репродуктологии, будут актуальны не менее 20 ближайших лет, и с каждым годом все более и более востребованы в связи с тем, что неблагоприятная экологичесхая обстановка и демографическая ситуация в нашей стране, по оценкам и прогнозам экспертов, будут сохранять негативные теңденции. Выполнение и реализация предложений и рекомендаций, полученных в результаге научных исследований и разработок в области экологической репродуктологии, могут повысить и сделать более надежной информационную обеспеченность управленческих структур, своевремснность и эффективность принимаемых на всех уровнях решений, касаюицися экологических аспектов охраны здоровья женшин и детей, при планировании профилактических, социальных, в том числе рекреационных и страховых мероприятий. В этом случае типология территорий, их картографирование по показателям репродуктивного здоровья надо будет учитывать при формировании цены жилой площади, дифференцированного налога на землю с учетом экологического риска. Эго цозволит также более рационально использовать средства, выделяемые на предотвращение экологических стресс-негативных воздействий на организм женцины, плоц и новорожденного. У'гочнение патогенеза экологически зависимой патологии репродуктивной функции позволит разработать обоснованные принципы, подходы и средства коррекции профилақтики неблагоприятного воздействия врсдных факторов среды обитания, даст возможность предотвратить часть релродуктивных потерь, сохранить и улучшить здоровье женщины, состояние ее плода и здоровье новорожденного, уменьшить частоту и тяжесть их психосоматической патологии и, следовательно, число детей и подростков - инвалидов с детства. И наконец, не за горами время, когда, на ряду с медицинским, будст внедрено экологическое страхование.

\section{Литература}

1. Айламазян Э.К. Антенатальная диагностика и коррекция нарушений развития плода // Рос. вестн. перинатологии и педиатрии - 1999. - T. 44, № 3. - C. 6-11.

2. Айламазян Э.Ж. Новые научные, организационные и управленческие подходы к комплексной фценке состояния окружающей среды // ॥ Межа. симп. Фонда мед. обме. на Японии, России и стран Северо-Восточной Азии. Про. грамма и тез. докл. 19-21 сент. $1994=$ The II-nd Inter symp. of Japan-Russia Med. exchange foundation and the region: Prog. and abstr. 19-21 sept. 1994. - Владивосток, 1994. C. 196 .

3. Айламззян Э.К. Репродуктивное здоровье женщины как критерий биоэкологической диагногтики и контроля окружающей среды // Ж. акуш. жен. болезн. - 1997, Вып. 1. C. $6-10$.

4. Айламазян Э.К., Беляева Т.В. Клинические и патофизио. логические проблемы экопогической репродуктологии // Общая и клиническая патофизиология: Мат. юбилейных Пашутинских чтений аКлиническая медицина, реабилитация и патофизиология”, 10-12 февр.1999 г. / Ред. В.10. Ша. нин; РВМА, каф. патофизиологии. - СПб.1999. -
С. $13-16$.

5. Айламазян Э.К., Беляева Т.В. Общие и частные пробле. мы экологической репродуктологии // *. ақуш. жен. 60 лезн. - 2003. - T. LII. Bвыл 2. - C. 4-10.

6. Айламазян Э.к., Беляева T.8. Теория и практика общей зкологической репродуктологии $/ / \mathcal{W}$ акуш жен. 60 лезн. - 2000. - T. XLIX, Вып 3 - C. 8-10.

7. Айламазян Э.К., Виноградова Е.Г. Гоказатели репродуктивной функции женщины для экологического мониторинга // Первый национальный конгресс по профилакти ческой медицине. Тез. докл: : 3 т., Санкт.Петербург, 17-21 мая 1994 г - СПб., 1994. - Т. 1. - С. 3. - реф. 7.

8. Айламазян Э.К., Виноградова Е.Г. Теоретическое и прак. тическое значение зкопогической репродуктологии в охране здоровья матери и ребенка // Профилактика на. рушений репродуктивного здоровья от профессиональных и зкологических факторов риска: Мат. межд конгресса. 29 июня-1 июля 2004 г. / Ред. Н. Ф. Измеров, И.В. Дардынская, О.С. Сивочалова и др. - Волгоград: Б.и., 2004. - С. 98-99

9. Айламазян Э.К. и др. Влияние зкологической обстанов. ки на репродуктивное здоровье женщины. Новый взгляд на проблему / Айламазян Э.К., Беляева Т.В., Виноградова Е.Г. // Вест. Рос. ассоц. акуш. -гин. - i996. - № 2. - С. 13-16.

10. Айламазян Э.К. и др. Новый метод экологического контро. ля по показателям репродуктивной функции женщины / Айламазян Э.К. Беляева Т.В., Виноградова Е.Г.// Тез. науч. докл. 3-й Межд. конф. "Экология и развитие Северо-запада России", 5-9 июля 1998 / Cогт. А.И. Демьяников. - СП6., 1998. - С. 240-241.

11. Айламазян Э.К. и др. Новые принципы оценки экологи. ческой безопасности на основе комплекса показателей репродуктивной функции женщины / Айламазян Э.К., 
Беляева Т.В., Виноградоеа Е.Г. // Критерии экологической безопасности: Мат. науч.-прак. конФ., 25-26 мая 1994 г. / РАМН СПб. науч. центр; Ред. С.Г. Инге-Вечтомов. СПб..1994- С. 106-107.

12. Айламазян Э.К. и др. Резолюция совместного Совещания Межведомственного Совета «Медихо-экологические про. блемы охраны репродуктивного здоровья работающих" и Проблемной комиссии "Экология и репродуктивная Функция женциины" Научного совета по акушерству и гинехологии РАMH от 11-12 мая 2000 r. / Айламазян 3.K. Сивочалова O.В., Беляева Т.В. // $*$. акуш. жен. болезн. 2000. - T. Xk|X, Вып 3. - C. 49

13. Значение интегральной оценки и контроля окружающей среды для профилактики экологически зависимой патологии репродуктивной системы жениины / Айламазян Э.К., Белнева Т.В., Виноградова Е.Г., Шутова И.А. // Eезоnасность и зкология Санкт-Петербурга: Тез. докл. науч. прак. конф. Ч. 1, 11-13 марта, 1999 г. / Мин. общ. и проф. образ. РФ. Админ. СПб., СПбГТу, Межд. акад наук экологии и безопасн. жизнедеятельности. - СТ6.1999. - С. 15-17.

14. Медико-экологические аспекты изучения репродуктивного здоровья / Айламазян Э.К., Беляева Т.В., Виногра. дова Е.Г., Шутова И.А. // Медико-экологические проблемы репродуктивного здоровья работающих: Тез. докл межд. конф. - М., 9-10 дек. 1998 г. - М, 1998. - C. 26

15. Окружающая среда и репродуктивная фунхция женщин / Айламазян Э.К., Беляева Т.В., Виноградова Е.Г., Шутова И.А. // Мат. VIIl Межд. симпозиума "Эколого-физиологические проблемы адаптации". Москва, 27-30 яне 1998 г. - M. 1998. - C. 11

16. Репродуктивное здоровье женщины қак критерий биоэкологической оценки охружающей среды / Айламазян. Э.К., Беляева Т.В., Виноградова Е.Г., Шутова И.А. // Вест. рос. ассоц. акуш.-гин. - 1997. - № 3. - С. 72-78.
17. Степанов M.Г. и др. Нарушение центральной регуляции репродуктивной функции под влиянием неблагоприятных факторов внешней среды / Степанов М.Г., Арутюнян А.В., Айламазян Э.К. // Вопр. мед. химии. - 1995. - Т. 41. № $5 .-$ C. 33-35

18. Стеланов М.Г.и др. Экспериментальное изучение влия ния экологически неблагоприятных факторов на репро. дуктивную функцию женского организма / Степанов М Г. Арутюнян А. 8. Айламазян Э.К. // Межд. мед. обзоры. 1995. - T. 3, № 2. - C. 81-83

19. Теоретические и прикладные аспекты общей экологической репродуктологии / Айламазян Э.К., Беляева Т.В., Арутюнян А.В., Степанов М.Г. // Экология челавека: от прошлого к будущему: Тез. докл. Всерос. науч. конф. - М. 2000. - C. 95-96.

\section{MAIN PROBLEMS AND PRACTICAL IMPORTANCE} OF ECOLOGICAL REPRODUCTOLOGY

\section{Ailamazyan E.K}

- Summary: Ecological reproductology is a field of medical knowicdge the subject of which is the study of ecology-dependent adaptive and pathologic reactions of human reproductive function. The sysicm of bioecological diagnostics of the environment by means of the woman's reproductive function indices allows to form a reliable information ground for taking administrative decisions and to prevent some of reproductive losses, to preserve and improve health of the woman and her posterity.

Key words: ccological reproductology; women's reproductive heaith; environment 